\title{
Risk factors for acute kidney injury after initial acute aortic dissection and their effect on long-term mortality
}

\author{
Akiko Kato*, Eri Ito, Naoki Kamegai, Minami Mizutani, Hiroya Shimogushi, Akihito Tanaka, Hibiki Shinjo, \\ Yasuhiro Otsuka, Daijo Inaguma and Asami Takeda
}

\begin{abstract}
Background: Several reports have discussed the risk factors for acute kidney injury (AKI) after thoracic aortic surgery and aortic dissection and the increased mortality in patients with AKI. However, there are few reports on the risk factors for AKI with combined medical and surgical treatment and the influence on mortality. The aim of this study was to clarify the risk factors and long-term effects of AKI on mortality and kidney function after acute aortic dissection in a cohort at our hospital.

Methods: We retrospectively investigated 96 patients with initial acute aortic dissection between April 2012 and January 2015. We divided the subjects into two groups: 65 with AKI and 31 without AKI using RIFLE criteria. The outcomes were all-cause mortality and the decrease in kidney function after 6 and 12 months. We extracted the risk factors for AKI by multivariate logistic regression using clinical parameters.
\end{abstract}

Results: A history of hypertension, type A aortic dissection, and low platelet levels were statistically significant factors to predict AKI after aortic dissection (odds ratio [OR] 9.1, $95 \%$ confidence interval [CI] 1.42-58.5, $p=0.02$; OR $25.2,95 \% \mathrm{Cl} 3.1-205.0, p=0.003$; OR 0.82, $95 \% \mathrm{Cl} 0.68-0.98, p=0.033$, respectively). Three patients with AKI died and 1 patient recovered from AKI. The kidney function in survivors was similar in those with and without AKI. Although there were no significant differences in long-term kidney function between groups, long-term mortality was worse in the AKI group ( $p=0.017)$.

Conclusions: Hypertension, type A aortic dissection, and low platelet levels were risk factors for AKI after aortic dissection, and AKI increased the 1-year all-cause mortality. A large-scale study is needed to verify our results.

Keywords: AKI, Aortic dissection, Renal function

Abbreviations: AKI, acute kidney injury; CT, computed tomography; eGFR, estimated glomerular filtration rate; GFR, glomerular filtration rate; LDL-C, low-density lipoprotein cholesterol; RRT, renal replacement therapy; sCr, serum creatinine; SD, standard deviation

\section{Background}

Aortic dissection is life-threatening. Stanford type A aortic dissection requires emergency surgery, because it can lead to a poor outcome. Stanford type B aortic dissection has a better outcome than type A and is often treated medically, even when presenting as complicated type B, which ultimately requires surgical treatment $[1,2]$. Several

\footnotetext{
* Correspondence: akiko.k198816@gmail.com

Department of Nephrology and Blood Purification Center, Japanese Red Cross Nagoya Daini Hospital, 2-9 Myokencho Showaku, Nagoya 466-8650, Japan
}

risk factors for in-hospital and long-term mortality have been reported [2-8]. Acute kidney injury (AKI) after acute aortic dissection and cardiothoracic surgery are predictive factors for mortality [9-13]. Several mechanisms for AKI after aortic dissection and surgery have been reported. Reduction in the renal artery lumen due to aortic dissection at the renal artery bifurcation and sepsis after surgery are possible mechanisms [14]. Other reports suggest that cardiac and cerebral malperfusion are both risk factors for in-hospital mortality; the order of importance of malperfusion is as follows: cardiac, cerebral, 
ileofemoral, renal, mesenteric, innominate, and spine [15]. Emergency surgery for type A aortic dissection using circulatory arrest influences AKI [9], and the mortality increases with severity of AKI [13, 16, 17]. Systemic mild-to-moderate hypothermia adapted to the duration of circulatory arrest is an effective method of organ protection in cardiovascular surgery [18], but deep hypothermia is associated with a greater risk of postoperative low cardiac output syndrome [19]. Preventing AKI is extremely important, so we examined the risk factors and possible methods of preventing AKI through postoperative care.

Several reports have discussed AKI after thoracic aortic surgery and aortic dissection, but there are few reports on conservative treatment. To prevent AKI, it is important to discuss the risk factors of AKI after aortic dissection using data obtained from medical records on admission, because most patients with dissection are transported by ambulance.

The aim of this study was to identify the risk factors for AKI after aortic dissection, including both medical and surgical treatment, and the impact of AKI on longterm mortality and renal function.

\section{Methods}

\section{Study population and data collection}

Between April 2012 and January 2015, 104 patients with initial aortic dissection within $48 \mathrm{~h}$ of onset were admitted to the Japanese Red Cross Nagoya Daini Hospital. Three patients who were on renal replacement therapy (RRT) and 1 who had a kidney transplant before admission were excluded because of the difficulty in measuring the progression of renal dysfunction. Four patients who died within $48 \mathrm{~h}$ after admission were also excluded because the data were inappropriate for evaluating renal dysfunction. Finally, 96 patients were included in this analysis. We also investigated the long-term mortality and renal function in 75 patients, excluding 15 who were transferred to another hospital or who were discharged against medical advice, and 6 who were followed up for less than 1 year. Patients were divided into two groups according to the presence or absence of AKI based on the RIFLE criteria. We defined the minimum serum creatinine $(\mathrm{sCr})$ level from 6 months before admission to 7 days after admission as the baseline $\mathrm{sCr}$ level and compared this with the maximum $\mathrm{sCr}$ level within 7 days of admission. In this study, we defined an increase in the $\mathrm{sCr}$ level to $\geqq 1.5$ times the baseline level as AKI. We did not include glomerular filtration rate (GFR) or urine output.

We collected data including age, sex, blood pressure, and medical history of hypertension, hyperlipidemia, diabetes, cardiovascular disease, and stroke, in addition to laboratory data, Stanford classification, and medication, by chart review.

This study was approved by the Japanese Red Cross Nagoya Daini Hospital ethics committee for clinical study and was conducted according to the ethical guidelines for clinical study published by the Ministry of Health and the Helsinki Declaration. The approval number is 1081 . The information about this study can be seen at the site of the Japanese Red Cross Nagoya Daini Hospital.

\section{Outcome}

The primary outcome was AKI after aortic dissection. The secondary outcome was the effect of AKI after aortic dissection on long-term mortality and renal function. The long-term mortality was evaluated by all-cause mortality for 1 year after aortic dissection, and renal function was assessed by comparing the $\mathrm{sCr}$ levels of patients with AKI to those without AKI at 6 and 12 months after onset.

\section{Statistical analysis}

Categorical data were presented as frequencies and percentages and continuous data were represented as median \pm standard deviation (SD). For comparison between groups, Fisher's exact test was performed for categorical data and the Mann-Whitney $U$ test for continuous data. Significance was defined as probability $p$ value $<0.05$. Stepwise multivariate logistic regression analysis was performed for age, sex, hypertension, diabetes, hemoglobin, albumin, estimated GFR (eGFR), platelets, fibrinogen, low-density lipoprotein cholesterol (LDL-C), and Stanford classification. Kaplan Meier curves and the log-rank test were used to demonstrate long-term mortality. Easy R was used for analysis.

\section{Results \\ Study population features}

There were 65 (68\%) patients with AKI; Table 1 shows the number of AKI patients classified according to the RIFLE criteria. The patient characteristics are presented in Table 2. A total of 96 patients were included after the exclusion of 8 patients. The median age was 69 years (range, 28 to 93 years), and 49 patients (51\%) were men.

Table 1 The number of patients classified according to RIFLE criteria

\begin{tabular}{ll}
\hline & Number (\%) \\
\hline Risk & $30(46 \%)$ \\
Injury & $25(38 \%)$ \\
Failure & $10(15 \%)$ \\
\hline
\end{tabular}

We defined an increase in the $\mathrm{s} C r$ level to $>1.5$ times the baseline level as risk, to $>2$ times the baseline levels as injury, and to $>3$ times the baseline levels or $\mathrm{sCr} \geqq 4 \mathrm{mg} / \mathrm{dl}$ as failure 
Table 2 Baseline characteristics

\begin{tabular}{|c|c|c|c|}
\hline & $\begin{array}{l}\text { No AKI group } \\
(N=31)\end{array}$ & $\begin{array}{l}\text { AKI group } \\
(N=65)\end{array}$ & $p$ value \\
\hline Age (years old) & $68.0 \pm 13.0$ & $70.0 \pm 14.0$ & 0.466 \\
\hline Gender (male) & $15(50 \%)$ & $34(52 \%)$ & 0.999 \\
\hline Body mass index $\left(\mathrm{kg} / \mathrm{m}^{2}\right)$ & $23.4 \pm 3.7$ & $22.3 \pm 4.3$ & 0.107 \\
\hline \multicolumn{4}{|l|}{ Comorbidity } \\
\hline Diabetes & $3(10 \%)$ & $5(8 \%)$ & 0.704 \\
\hline Hypertension & $16(53 \%)$ & $42(71 \%)$ & 0.106 \\
\hline Hyperlipidemia & $15(50 \%)$ & $15(24 \%)$ & 0.018 \\
\hline $\mathrm{eGFR}<60\left(\mathrm{ml} / \mathrm{min} / 1.73 \mathrm{~m}^{2}\right)$ & $13(43 \%)$ & $39(60 \%)$ & 0.183 \\
\hline Coronary artery disease & $3(10 \%)$ & $6(10 \%)$ & 0.999 \\
\hline Stroke & $6(20 \%)$ & $6(10 \%)$ & 0.200 \\
\hline \multicolumn{4}{|l|}{ Medication } \\
\hline Anticoagulant & 1 (3 \%) & $1(2 \%)$ & 0.999 \\
\hline Antiplatelet & $3(10 \%)$ & $6(9 \%)$ & 0.999 \\
\hline Ca blocker & $5(17 \%)$ & $15(27 \%)$ & 0.423 \\
\hline RAS inhibitor & $4(13 \%)$ & $16(29 \%)$ & 0.179 \\
\hline Statin & $6(20 \%)$ & $8(14 \%)$ & 0.542 \\
\hline \multicolumn{4}{|l|}{ Clinical presentation } \\
\hline Systolic BP (mmHg) & $149 \pm 37$ & $133 \pm 45$ & 0.053 \\
\hline Diastolic BP (mmHg) & $82 \pm 19$ & $72 \pm 26$ & 0.026 \\
\hline Stanford A & $8(26 \%)$ & $50(77 \%)$ & $<0.001$ \\
\hline CTR (\%) & $57.8 \pm 4.9$ & $59.7 \pm 5.7$ & 0.105 \\
\hline Mediastinal extension & $9(29 \%)$ & $42(65 \%)$ & 0.002 \\
\hline $\begin{array}{l}\text { Dissection of renal artery } \\
\text { branch }\end{array}$ & $13(42 \%)$ & $41(63 \%)$ & 0.080 \\
\hline Operation & $3(9.3 \%)$ & $43(66.2 \%)$ & $<0.001$ \\
\hline Operation time (min) & $310.0 \pm 66.5$ & $423.0 \pm 141.7$ & 0.106 \\
\hline $\begin{array}{l}\text { Cardiopulmonary bypass } \\
\text { time (min) }\end{array}$ & $177.5 \pm 56.2$ & $209.4 \pm 77.9$ & 0.533 \\
\hline $\begin{array}{l}\text { Intraoperative blood } \\
\text { loss (ml) }\end{array}$ & $1073.8 \pm 432.2$ & $2950.2 \pm 2522.3$ & 0.059 \\
\hline $\begin{array}{l}\text { Perioperative blood } \\
\text { transfusion unit }\end{array}$ & $3.3 \pm 7.7$ & $23.0 \pm 27.0$ & $<0.001$ \\
\hline Hospital stay (day) & $21.8 \pm 8.5$ & $33.7 \pm 23.2$ & 0.002 \\
\hline \multicolumn{4}{|l|}{ Admission laboratory date } \\
\hline WBC $\left(\times 10^{3} / \mathrm{mm}^{3}\right)$ & $10.7 \pm 3.2$ & $11.8 \pm 5.3$ & 0.586 \\
\hline Hemoglobin (g/dl) & $13.8 \pm 1.6$ & $13.2 \pm 1.9$ & 0.173 \\
\hline Platelet $\left(\times 10^{4} / \mathrm{mm}^{3}\right)$ & $20.0 \pm 8.0$ & $16.0 \pm 5.0$ & 0.013 \\
\hline $\mathrm{D}$ dimer $(\mu \mathrm{g} / \mathrm{ml})$ & $9.8 \pm 15.0$ & $47.3 \pm 63$ & $<0.001$ \\
\hline Fibrinogen (mg/dl) & $397 \pm 188$ & $260 \pm 127$ & $<0.001$ \\
\hline FDP $(\mu \mathrm{g} / \mathrm{ml})$ & $36.6 \pm 48.9$ & $167 \pm 203$ & 0.016 \\
\hline Albumin $(\mathrm{g} / \mathrm{dl})$ & $4.01 \pm 0.47$ & $3.64 \pm 0.51$ & 0.070 \\
\hline $\mathrm{LDH}(\mathrm{IU} / \mathrm{L})$ & $223 \pm 59$ & $320 \pm 253$ & $<0.001$ \\
\hline CK (IU/L) & $97 \pm 59$ & $115 \pm 89$ & 0.552 \\
\hline BUN (mg/dl) & $17.4 \pm 8.6$ & $20.3 \pm 8.1$ & 0.022 \\
\hline
\end{tabular}

Table 2 Baseline characteristics (Continued)

\begin{tabular}{llll}
\hline Creatinine $(\mathrm{mg} / \mathrm{dl})$ & $0.91 \pm 0.47$ & $1.01 \pm 0.42$ & 0.100 \\
$\mathrm{eGFR}\left(\mathrm{ml} / \mathrm{min} / 1.73 \mathrm{~m}^{2}\right)$ & $62.5 \pm 16.1$ & $56.2 \pm 18.1$ & 0.044 \\
$\mathrm{UA}(\mathrm{mg} / \mathrm{dl})$ & $5.73 \pm 2.06$ & $5.87 \pm 1.38$ & 0.740 \\
$\mathrm{CRP}(\mathrm{mg} / \mathrm{dl})$ & $2.3 \pm 3.7$ & $1.3 \pm 2.8$ & 0.257 \\
$\mathrm{TG}(\mathrm{mg} / \mathrm{dl})$ & $119 \pm 65.0$ & $87.5 \pm 51.1$ & 0.013 \\
$\mathrm{~T}-\mathrm{CHO}(\mathrm{mg} / \mathrm{dl})$ & $203 \pm 42.2$ & $172 \pm 38.5$ & 0.101 \\
$\mathrm{LDL}-\mathrm{C}(\mathrm{mg} / \mathrm{dl})$ & $121 \pm 41.2$ & $98.5 \pm 28.0$ & 0.016 \\
$\mathrm{HDL}-\mathrm{C}(\mathrm{mg} / \mathrm{dl})$ & $44.5 \pm 8.19$ & $50.8 \pm 14.8$ & 0.091 \\
$\mathrm{HbA} 1 \mathrm{c}(\mathrm{NGSP} \%)$ & $5.94 \pm 0.61$ & $5.76 \pm 0.61$ & 0.172 \\
\hline Date presented as $n$ (\%) or median \pm SD & & \\
RAS renin angiotensin system, BP blood pressure, CTR cardio thoracic ratio
\end{tabular}

Type A aortic dissection was seen in 58 patients (60\%); 45 patients ( $47 \%$ ) who underwent emergency surgery all had type A aortic dissection.

\section{Primary outcome}

In the univariate analysis, there were significant differences between patients with and without AKI according to history of hyperlipidemia, laboratory data (congealing fibrinogenolysis system, albumin, lactate dehydrogenase, eGFR, blood urea nitrogen, triglyceride, and LDL-C), diastolic blood pressure on admission, Stanford type A aortic dissection, widened mediastinum, surgery, perioperative blood units transfused, and hospital stay (Table 3). Fluid resuscitation before diagnostic computed tomography $(\mathrm{CT})$ with contrast medium was not examined in this study. The dose of contrast medium was usually twice the volume by body weight or $100 \mathrm{ml}$. In 65 patients $(68 \%)$ with AKI, $4(4 \%)$ required blood purification therapy. Subsequently, 3 patients (3\%) died, and 1 patient (1\%) recovered from AKI. In order to clarify the risk factors for AKI after aortic dissection, we examined the differences between the 2 groups with multivariate analysis (Table 4). When we adjusted the background between the 2 groups for age, sex, hypertension, diabetes, eGFR, platelets, fibrinogen, LDL-C, and Stanford criteria, we found that more patients had a history of hypertension, type A aortic dissection, and low platelet levels in the AKI group (odds ratio [OR] 9.1, $95 \%$ confidence interval [CI] 1.42-58.5, $p=0.02$; OR 25.2, $95 \%$ CI 3.1-205.0, $p=0.003$; OR 0.82, $95 \%$ CI $0.68-0.98, p=0.033$, respectively). Figure 1 shows that there were significant differences between patients with and without AKI and patients with AKI in terms of according to history of hypertension, low platelet count, and Stanford type A aortic dissection.

\section{Secondary outcome}

Next, we plotted the Cr levels after aortic dissection in patients with or without AKI according to baseline $\mathrm{Cr}$ 
Table 3 Univariate analysis of risk factor for acute kidney injury

\begin{tabular}{|c|c|c|c|}
\hline & Odds ratio & $95 \% \mathrm{Cl}$ & $p$ value \\
\hline Age (years old) & 1.01 & $0.978-1.040$ & 0.559 \\
\hline Gender (male) & 0.91 & $0.384-2.170$ & 0.834 \\
\hline Body mass index $\left(\mathrm{kg} / \mathrm{m}^{2}\right)$ & 0.94 & $0.845-1.040$ & 0.227 \\
\hline \multicolumn{4}{|l|}{ Comorbidity } \\
\hline Diabetes & 0.75 & $0.166-3.360$ & 0.704 \\
\hline Hypertension & 2.16 & $0.868-5.380$ & 0.098 \\
\hline Hyperlipidemia & 0.32 & $0.127-0.802$ & 0.015 \\
\hline $\mathrm{eGFR}<60\left(\mathrm{ml} / \mathrm{min} / 1.73 \mathrm{~m}^{2}\right)$ & 0.98 & $0.953-1.000$ & 0.100 \\
\hline Coronary artery disease & 1.04 & $0.241-4.460$ & 0.961 \\
\hline Stroke & 1 & $0.999-1.000$ & 0.419 \\
\hline \multicolumn{4}{|l|}{ Medication } \\
\hline Anticoagulant & 0.51 & $0.031-8.430$ & 0.637 \\
\hline Antiplatelet & 1.04 & $0.241-4.480$ & 0.960 \\
\hline Ca blocker & 1.76 & $0.567-5.440$ & 0.329 \\
\hline RAS inhibitor & 2.50 & $0.750-8.340$ & 0.136 \\
\hline Statin & 0.64 & $0.200-2.050$ & 0.453 \\
\hline \multicolumn{4}{|l|}{ Clinical presentation } \\
\hline Systolic BP (mmHg) & 0.98 & $0.965-1.000$ & 0.057 \\
\hline Diastolic BP (mmHg) & 0.99 & $0.981-1.000$ & 0.086 \\
\hline Stanford A & 22.34 & $2.700-203.000$ & $<0.001$ \\
\hline CTR (\%) & 1.07 & $0.982-1.160$ & 0.130 \\
\hline Mediastinal extension & 4.26 & $1.680-10.800$ & 0.002 \\
\hline Dissection of renal artery branch & 2.23 & $0.926-5.390$ & 0.074 \\
\hline Operation & 16.40 & $4.490-60.100$ & $<0.001$ \\
\hline Operation time (min) & 1.01 & $0.996-1.020$ & 0.161 \\
\hline $\begin{array}{l}\text { Cardiopulmonary bypass } \\
\text { time (min) }\end{array}$ & 1.02 & $0.988-1.040$ & 0.273 \\
\hline Intraoperative blood loss (ml) & 1.00 & $1.000-1.000$ & 0.171 \\
\hline Hospital stay (day) & 1.07 & $1.020-1.120$ & 0.007 \\
\hline $\begin{array}{l}\text { Perioperative blood transfusion } \\
\text { unit }\end{array}$ & 1.110 & $1.010-1.160$ & $<0.001$ \\
\hline \multicolumn{4}{|l|}{ Admission laboratory date } \\
\hline WBC $\left(\times 10^{3} / \mathrm{mm}^{3}\right)$ & 1.06 & $0.958-1.170$ & 0.287 \\
\hline Hemoglobin (g/dl) & 0.83 & $0.645-1.070$ & 0.145 \\
\hline Platelet $\left(\times 10^{4} / \mathrm{mm}^{3}\right)$ & 0.88 & $0.811-0.964$ & 0.005 \\
\hline $\mathrm{D}$ dimer $(\mu \mathrm{g} / \mathrm{ml})$ & 1.04 & $1.010-1.080$ & 0.013 \\
\hline Fibrinogen (mg/dl) & 0.99 & $0.991-0.998$ & $<0.001$ \\
\hline $\mathrm{FDP}(\mu \mathrm{g} / \mathrm{ml})$ & 1.01 & $0.999-1.020$ & 0.068 \\
\hline Albumin (g/dl) & 0.19 & $0.065-0.575$ & 0.003 \\
\hline LDH (IU/L) & 1.01 & $1.000-1.020$ & 0.005 \\
\hline CK (IU/L) & 1.00 & $0.997-1.010$ & 0.330 \\
\hline BUN (mg/dl) & 1.05 & $0.986-1.120$ & 0.129 \\
\hline Creatinine (mg/dl) & 1.84 & $0.550-6.130$ & 0.324 \\
\hline $\operatorname{eGFR}\left(\mathrm{ml} / \mathrm{min} / 1.73 \mathrm{~m}^{2}\right)$ & 0.98 & $0.953-1.000$ & 0.100 \\
\hline
\end{tabular}

Table 3 Univariate analysis of risk factor for acute kidney injury (Continued)

\begin{tabular}{llll}
\hline UA $(\mathrm{mg} / \mathrm{dl})$ & 1.06 & $0.662-1.690$ & 0.809 \\
$\mathrm{CRP}(\mathrm{mg} / \mathrm{dl})$ & 0.94 & $0.882-1.070$ & 0.360 \\
$\mathrm{TG}(\mathrm{mg} / \mathrm{dl})$ & 0.99 & $0.981-1.000$ & 0.048 \\
$\mathrm{~T}-\mathrm{CHO}(\mathrm{mg} / \mathrm{dl})$ & 0.98 & $0.961-1.000$ & 0.059 \\
$\mathrm{LDL}-\mathrm{C}(\mathrm{mg} / \mathrm{dl})$ & 0.98 & $0.962-0.997$ & 0.026 \\
$\mathrm{HDL}-\mathrm{C}(\mathrm{mg} / \mathrm{dl})$ & 1.04 & $0.997-1.090$ & 0.066 \\
HbA1C $(\mathrm{NGSP} \%)$ & 0.61 & $0.230-1.600$ & 0.313 \\
\hline C confidence interval & & &
\end{tabular}

(on admission), peak $\mathrm{Cr}$ (at any time after onset), and after 6 and 12 months. Figure 2 shows that there was a significant difference between groups at peak $\mathrm{Cr}(p<$ 0.001 ), but there were no significant differences between groups in terms of in sCr levels at 6 and 12 months after admission. This indicates that kidney function in survivors was similar in those with and without AKI. Finally, we examined all-cause mortality after aortic dissection in patients with or without AKI. Figure 3 showed a significant difference in 5 all-cause mortality between the 2 groups $(p<0.05)$.

\section{Discussion}

Almost all patients were transported to the hospital urgently, as acute aortic dissection is a life-threatening. We usually receive consultations for patients with known AKI, but preventing AKI is important. If we can predict the risk factors for AKI from the medical history, laboratory data on admission, and the clinical presentation of aortic dissection, consultation with a nephrologists can be ordered before dropping renal function declines. We cooperate to participate in volume fluid and medical control management at an early stage after admission and perhaps we can also prevent AKI. Patients with medical A history of hypertension, low platelet count, and Stanford type A were the risk factors for AKI, and we had better require intervention and medical management. This is was a small number of retrospective observational study, and a small number of patients were separated into 2 groups in this study. We therefore need more patients to investigate the risk factors for AKI and mortality.

Table 4 Multivariate analysis of risk factor for acute kidney injury

\begin{tabular}{llll}
\hline & Odds ratio & $95 \% \mathrm{Cl}$ & $p$ value \\
\hline Hypertension & 9.10 & $1.420-58.500$ & 0.020 \\
Stanford A & 25.20 & $3.100-205.00$ & 0.003 \\
Platelet $\left(\times 10^{4} / \mathrm{mm}^{3}\right)$ & 0.82 & $0.683-0.984$ & 0.033 \\
\hline
\end{tabular}

Adjusted for age, sex, hypertension, diabetes, hemoglobin level, albumin level, eGFR, platelet level, fibrinogen level, LDL-C level, and Stanford A criteria $\mathrm{Cl}$ confidence interval 


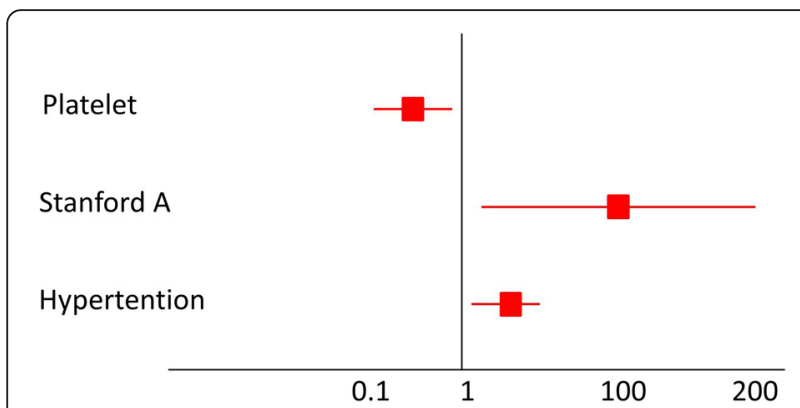

Fig. 1 Adjusted for age, sex, hypertension, diabetes, hemoglobin level, albumin, eGFR, platelet level, fibrinogen level, LDL-C level, and Stanford A criteria. There were significant differences between patients with and without AKI for history of hypertension, low platelet count, and Stanford type A aortic dissection

A retrospective study regarding the incidence and risk factors for AKI after thoracic aortic surgery for aortic dissection determined that preoperative $\mathrm{sCr}$ level and cardiopulmonary bypass duration longer than $180 \mathrm{~min}$ were independent risk factors for AKI [8]. In another study, extracorporeal circulation time, body mass index, perioperative peak serum C-reactive protein concentration, renal malperfusion, and perioperative sepsis were risk factors for AKI in patients with Stanford type A aortic dissection who underwent surgery [12]. Another study about on the incidence and risk factors of for AKI after DeBakey type III aortic dissection determined that a history of hypertension, electrocardiographic ST$\mathrm{T}$ changes, DeBakey type IIIb, and sCr level on admission were risk factors for AKI [20]. Several risk factors were reported in the previous study, and the risk factors were differentiated depending on the patient background and perioperative care. In previous studies, the
RIFLE criteria were used to determine the presence or absence of AKI; no studies considered urinary volume. In this study, we also used the RIFLE criteria to determine the presence or absence of AKI, because we investigated the transition change in $\mathrm{sCr}$ within 7 days of admission. In the previous studies, the preoperative $\mathrm{sCr}$ level or the $\mathrm{sCr}$ level on admission was defined as the baseline, but the $\mathrm{sCr}$ level several months before the acute aortic dissection was not measured in almost all of the patients included in the studies. In this study, renal function 6 months before admission was measured only in 9 patients, because almost all of the patients in this study came to our hospital for the first time. We defined the baseline $\mathrm{sCr}$ as the lowest level in 7 days after admission; therefore, the sCr level on admission was probably higher, and the $\mathrm{sCr}$ level after admission was lower than the baseline level.

A history of hypertension was probably related to Stanford type A or extensive aortic dissection, and led to disseminated intravascular coagulation, which in turn led to the abnormality in the congealing fibrinogenolysis system and a low platelet count. Aortic dissection or surgery may decrease the platelet count, but the baseline used in this study was collected on admission and also before surgery. Therefore, abnormality of the congealing fibrinogenolysis system and a low platelet count were caused not only by surgery but also by aortic dissection itself. Other than these two abnormalities, there were no significant bleeding disorders in groups with and without AKI.

We showed that AKI after aortic dissection was a predictor of 1-year mortality, but renal function was not damaged but significantly affected. A retrospective study of the incidence and risk factors for AKI after thoracic

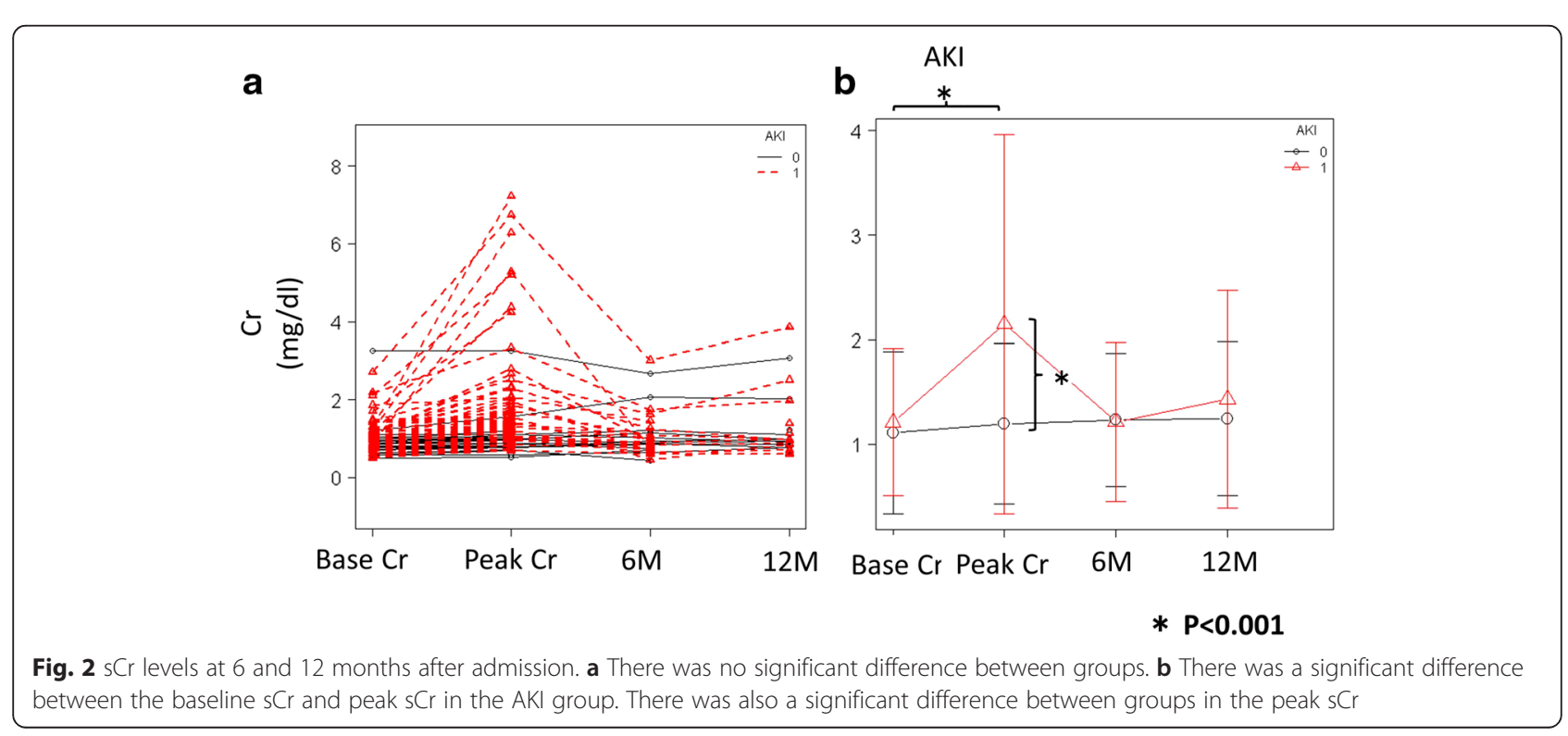




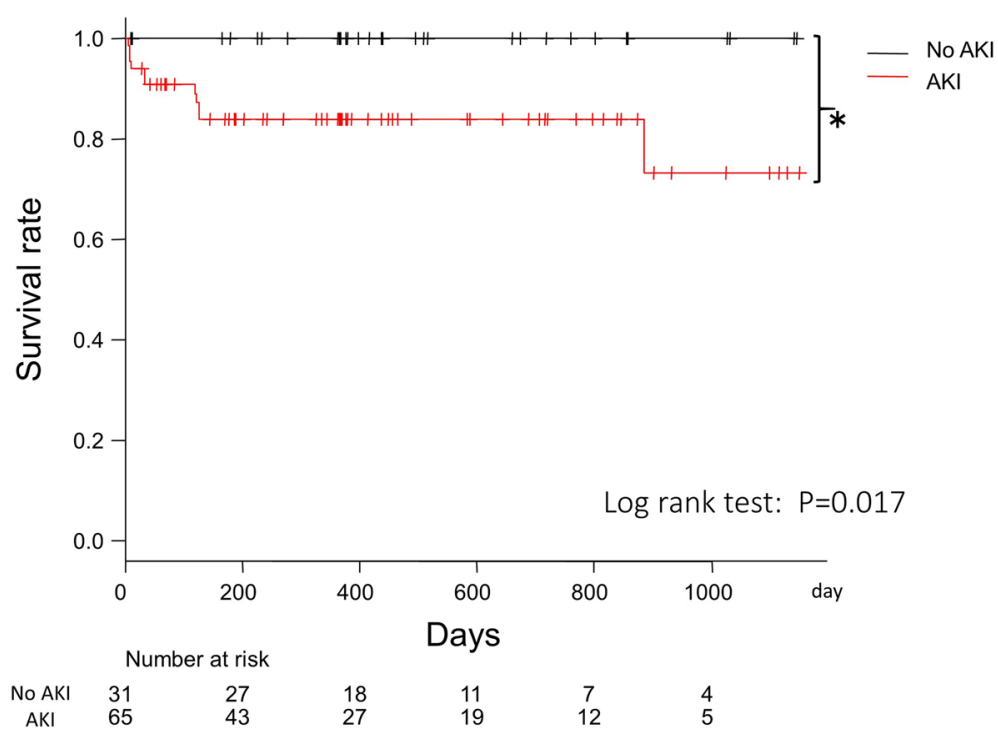

Fig. 3 Mortality after admission. There was a significant difference between groups. No patients died among those without AKI

aortic surgery for Stanford type A dissection reported that AKI worsened the in-hospital, 30-day, and 1-year mortality $[8,12]$. Another study on the incidence and risk factors for AKI after DeBakey type III aortic dissection also reported that AKI worsened mortality, because in-hospital complications were higher in patients with AKI [20]. In this study, the median age was higher, and the percentage of Stanford type A was the same as in previous studies. All surgeries were emergency, and all patients who underwent surgery had Stanford type A aortic dissection. Emergency surgery and perioperative complications are more likely to predispose to higher mortality than Stanford type B.

There are few studies on long-term mortality. In this study, renal function at 6 and 12 months after admission was relatively preserved, and there were no statistically significant differences between groups. Although renal function was relatively preserved, patients with AKI had a longer hospital stay required transfer for rehabilitation. Impaired activities of daily living may contribute to higher mortality.

This study had some limitations. First, this was a single-center study. There are differences in surgical technique and treatment between hospitals, so the risk factors for AKI and mortality may vary. Because risk factors and mortality vary among racial groups, multicenter studies are needed worldwide. Second, very few of the patients visited the hospital regularly before they were admitted; we therefore did not know their baseline renal functions. We defined the lowest $\mathrm{sCr}$ level in the hospital 7 days after admission as the baseline. Third, there were more patients with Stanford type A aortic dissection who were not followed up than patients with Stanford type B, because many with Stanford type A transferred for rehabilitation. Finally, a multicenter, large-scale study on the unsolved issues described in this study is needed in the future.

\section{Conclusions}

A history of hypertension, low platelet count, and Stanford type A aortic dissection on admission could be risk factors for AKI after initial aortic dissection, and the all-cause mortality was higher in patients with AKI than in patients without AKI.

\section{Authors' contributions}

AK planned the study, collected the data, and performed the statistical analysis. AT and HS participated in the design and coordination and helped to perform the statistical analysis. DI conceived the study, participated in its design and coordination, and helped to draft the manuscript. EI, NK, MM, HS, YO, and AT participated in the design and coordination. All authors read and approved the final manuscript.

\section{Competing interests}

The authors declare that they have no competing interests.

Received: 26 February 2016 Accepted: 20 August 2016

Published online: 08 October 2016

\section{References}

1. Nienaber CA, Eagle KA. Aortic dissection: new frontiers in diagnosis and management. Part II: therapeutic management and follow-up. Circulation. 2003;108:772-8.

2. Suzuki T, Mehta RH, Ince $\mathrm{H}$, et al. Internal Registry of Aortic Dissection. Clinical profiles and outcomes of acute type B aortic dissection in the current era: lessons from the International Registry of Aortic Dissection (IRAD). Circulation. 2003;108 Suppl 1:11312-7.

3. Nallamothu BK, Mehta RH, Saint S, et al. Syncope in acute aortic dissection: diagnostic, prognostic, and clinical implications. Am J Med. 2002;113:468-71.

4. Stamou SC, Hagberg RC, Khabbaz KR, et al. Is advanced age a contraindication for emergent repair of acute type A aortic dissection? Interact Cardiovasc Thorac Surg. 2010;10:539-44. 
5. Onitsuka S, Akashi H, Tayama K, et al. Long-term outcome and prognostic predictors of medically treated acute type B aortic dissection. Ann Thorac Surg. 2004;78:1268-73.

6. Booher AM, Isselbacher EM, Nienaber CA, et al. Ascending thoracic aorta dimension and outcomes in acute type B dissection (from the International Registry of Acute Aortic Dissection [IRAD]). Am J Cardiol. 2011;107:315-20.

7. Santini F, Montalbano G, Casali G, et al. Clinical presentation is the main predictor of in-hospital death for patients with acute type A aortic dissection admitted for surgical treatment: a 25 years experience. Int $J$ Cardiol. 2007;115:305-11

8. Roh GU, Lee JW, Nam SB, et al. Incidence and risk factors of acute kidney injury after thoracic aortic surgery for acute dissection. Ann Thorac Surg. 2012;94:766-71.

9. Brown JR, Kraner RS, Coca SG, et al. Duration of acute kidney injury impacts long-term survival after cardiac surgery. Ann Thorac Surg. 2010;90:1142-8.

10. Robert AM, Kramer RS, Dacey $\sqcup$, et al. Cardiac surgery associated acute kidney injury: a comparison of two consensus criteria. Ann Thorac Surg. 2010;90:1939-43.

11. Mariscalco G, Lorusso R, Dominici C, et al. Acute kidney injury: a relevant complication after cardiac surgery. Ann Thorac Surg. 2011;92:1539-47.

12. Ko T, Higashitani M, Sato A, et al. Impact of acute kidney injury on early to long term outcome in patients who underwent surgery for type A acute aortic dissection. Am J Cardiol. 2015;116:463-8.

13. Tsai HS, Tsai FC, Chen YC, et al. Impact of acute kidney injury on one-year survival after surgery for aortic dissection. Ann Thorac Surg. 2012;94:1407-12.

14. Zarjou A, Agarwal A. Sepsis and acute kidney injury. J Am Soc Nephrol. 2011;22:999-1006.

15. Geirsson A, Szeto WY, Pochettino A, et al. Significance of malperfusion syndromes prior to contemporary surgical repair for acute type A dissection: outcomes and need for additional revascularizations. Eur J Cardiothorac Surg. 2007;32:255-62.

16. D'Onofrio A, Cruz D, Bolgan I, et al. RIFLE criteria for cardiac surgeryassociated acute kidney injury: risk factors and outcomes. Congest Heart Fail. 2010;16 Suppl 1:S32-6.

17. Arnaoutakis GJ, Bihorac A, Martin TD, et al. RIFLE criteria for acute kidney injury in aortic arch surgery. J Thorac Cardiovasc Surg. 2007;134:1554-60.

18. Urbanski PP, Lenos A, Bouqioukakis $\mathrm{P}$, et al. Mild-to-moderate hyperthermia in aortic arch surgery using circulatory arrest: a change of paradigm? Eur J Cardiothorac Surg. 2012:41:185-91.

19. Yoo JS, Kim JB, Joo Y, et al. Deep hypothermic circulatory arrest versus nondeep hypothermic beating heart in descending thoracic or thoracoabdominal aortic surgery. Eur J Cardiothorac Surg. 2014;46:678-84.

20. Takahashi T, Hasegawa $\mathrm{T}$, Hirata $\mathrm{N}$, et al. Impact of acute kidney injury on in-hospital outcome in patients with DeBakey type III acute aortic dissection. Am J Cardiol. 2014;113:1904-10.

\section{Submit your next manuscript to BioMed Central and we will help you at every step:}

- We accept pre-submission inquiries

- Our selector tool helps you to find the most relevant journal

- We provide round the clock customer support

- Convenient online submission

- Thorough peer review

- Inclusion in PubMed and all major indexing services

- Maximum visibility for your research

Submit your manuscript at www.biomedcentral.com/submit

C Biomed Central 